Hanne Kirstine Adriansen

Lene Møller Madsen

\section{Using facilitated study groups to improve student retention}

Danmarks Pædagogiske Universitetsskole, Aarhus Universitet

Working Paper, Faciliteringsfeltet, Organisation og Læring, 2010 
Titel:

Using facilitated study groups to improve student retention

Working Paper udgivet af:

Danmarks Pædagogiske Universitetsskole, AU

Institut for Læring, Organisation og Læring 2010

Forfattere:

Hanne Kirstine Adriansen

Associate professor, $\mathrm{PhD}$

Department of Learning

Danish School of Education

Aarhus University

Lene Møller Madsen

Associate Professor, PhD

Department of Science Education

University of Copenhagen

ISBN: 978-87-7507-357-3 (e-udgave)

DOI: 10.7146/aul.108.103

(c) 2010 Forfatterne

1. udgave 2010

Omslag og grafisk design: Knud Holt Nielsen

Kopiering tilladt med tydelig kildeangivelse

ISBN: 978-87-7430-191-2 


\section{Introduction}

According to statistics from the OECD, one-third of students in OECD countries drop out of their degree programme before they complete their first degree (OECD, 2006, 2009). Universities and other higher education institutions have increasing economic interests in the students finishing their degrees; therefore they tend to focus on activities that can increase retention. Likewise, there are an increasing number of researchers addressing the problem of retention and its opposite - attrition. According to Seymour and Hewitt (1997), the early attrition research was dominated by the view that students themselves were the problem. It was believed that students left because they had made wrong choices, were unprepared, had insufficient interest, lacked the ability or hard work to complete a higher education, or they discovered a passion for another discipline. However, research in the late 1990s showed that there was no evidence of these beliefs (Seymour, 2002). Instead it was found that most often students decided to drop out in response to a set of problems experienced by both leavers and non-leavers. It was documented that problems relating to the structure of the educational experience and the culture of the discipline made a much greater contribution to attrition than the individual inadequacies of students or the appeal of other degree programmes (Seymour and Hewitt, 1997). Further it was found that leaving university often is a culmination of a process lasting from a few months to several years based on 'a dialogue with self and others over time, in which students were drawn back and forth between the options that seemed open to them' (Seymour and Hewitt, 1997, p. 393). Other studies have confirmed that leaving the university is usually a complex process influenced by a number of interacting factors (e.g. Ozga and Sukhnandan, 1998). In particular academic and social integration into the degree programme has been shown to be important for students' well-being ${ }^{1}$ and hence the ability for universities to maintain enrolled students (Braxton et al., 2000; Tinto 1986, 1993). Thereby, academic and social integration of students has become interesting from an institutional perspective within higher education because it deals with student dropout which is an economic problem for many universities. Several studies have addressed the issues of retention often focusing on specific contexts and groups of students (for a review see Ulriksen et al., forthcoming). This study further explores the students' academic and social integration in relation to retention.

In the fall of 2008, a project aiming at increasing the students' well-being was initiated at a postgraduate programme at a Danish university. The project

\footnotetext{
${ }^{1}$ We use well-being to denote student satisfaction with their degree programme and study environment.
} 
consisted of three elements: facilitated study groups, a student bar with facilitated activities, and academic identity events. The goals were twofold: to increase the students' social and academic integration and thereby retention and to achieve this with minimal teacher involvement. The activities were outside the classroom and none of them was mandatory. The project is different from other projects focusing on social and academic integration in a number of ways. As mentioned above, we tried to obtain academic integration outside the classroom not involving faculty. In some ways this is in contrast to Tinto's claim that 'if academic and social involvement or integration is to occur, it must occur in the

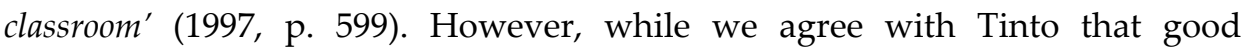
conditions for academic integration can be obtained within the classroom, we also acknowledge the realities of many universities today, where faculty resources are limited. Therefore we decided to study what could be achieved in facilitated study groups which is an academic activity, but outside the classroom. Study groups are not something new, but the use of facilitation for guiding the work in the groups is. The study groups functioned as a place for peer learning. Often peer learning activities use older students as peers. But in this project, peer learning was facilitated by 'real' peers from the same cohort. Apart from these three differences (minimal teacher involvement, the use of facilitation techniques, and having 'real' peers), which were deliberate parts of the design of the project, there was also another difference from similar studies: it concerned a postgraduate degree programme with mature students. As Boud and Lee (2005) have noticed, the majority of research on peer learning concern undergraduate programmes. We hope this paper will contribute to the call for more research at postgraduate level.

To report from this project the remainder of the paper is organised in three main sections as follows. In the next section, we briefly introduce the research field concerning retention in higher education, present the concept social and academic integration and some basic ideas regarding peer learning. Following this, we analyse the case - how to enhance social and academic integration. This is initiated by giving two primers, one on the Danish university system and one on facilitation. This contextualisation is necessary for understanding the findings of the study and the general bearings it has for using facilitated study groups as a means to enhance social and academic integration. The paper ends with a discussion and some concluding remarks 


\section{Attrition and integration}

This paper is written against the backdrop that there has been an increased focus on retention among higher education institutions in the past decades. Attrition is seen both at universities with tuition fees and where education is free; and students drop out of degree programmes with strong terms of admission as well as from those with free admission. Hence, attrition is a general problem. But to whom is it a problem? and how can we solve it? This is the concern of this section.

\subsection{What is attrition and to whom is it a problem?}

As Hovdhaugen (2009) has pointed out, there is a range of different concepts relating to students deciding to leave their study programme. In the UK, the phenomenon is usually described as 'non-completion' or 'non-continuing students', while in the US it is more common to talk about 'dropout' or 'student departure'. In this paper, these concepts are used interchangeably and all relate to the case when a student leaves university without completing a degree and states that she/he has no intention of returning to higher education. Likewise we use the concept attrition about dropout. Retention is used to denote the opposite - that students stay and complete their degree. In the case where a student leaves an institution without obtaining a degree but does in fact move to another higher education institution, we talk about transfer. This reflects the fact discussed by Hovdhaugen (2009) that often a high percentage of all university students leave the initial institution before degree completion, but the majority of the leavers transfer to another higher education institution, and only a smaller percentage of the students leave higher education without completing a degree at all. Tinto (1993) suggests a distinction between 'institutional departures' (students transferring from one to another higher education institution), and 'system departures' (students leaving the higher education system altogether). For the department and the degree programmes both institutional and system of departures are an economic problem, however, for the individual student and the society in general, system departure is a more serious problem than an institutional departure. Because this means that the student does not receive an education.

For the study of student dropout from an institutional perspective, Tinto and his interactionalist theory of college students' departure has received nearparadigmatic status (Braxton et al., 1997; Pascarella and Terenzini, 2005). In line with Seymour and Hewitt (1997), Tinto criticises the psychological approach for understanding students' departure for focusing on traits of the individual, thus 
making the student success dependant on 'the ability or willingness of the individual' and 'more important, such models invariably see student departure as reflecting some shortcoming and/or weakness in the individual' (Tinto, 1993, p. 85). Instead he emphasises a sociological approach where the student's decision to depart from or stay at university is studied by looking at the student's goals and commitments based on his/her social and academic integration at the university. This approach sees the university as a social system that works within a set of other social systems and students are engaged simultaneously in more systems (Tinto, 1993).

These different approaches bear meaning to how we understand and interpret student dropout, to whom it is a problem, and how it should be solved. With Tinto's focus on social and academic integration, student departure is perceived as a problem for institutions rather than for the individual student leaving. Consequently, attrition should be addressed at the institutional level.

\subsection{How can attrition be addressed? Increased social and academic integration}

In this paper, we use an institutional perspective for addressing attrition. We do this because we are inspired by Tinto's focus on social and academic integration as a means to enhance retention. It is thought that successful integration in both of these spheres reduces the likelihood of student withdrawal (Tinto, 1975; Wilcox et al., 2005). As Tinto explains: 'The more students are involved, academically and socially, in shared learning experiences that link them as learners with their peers, the more likely they are to become more involved in their own learning and invest the time and energy needed to learn' (1997, p. 617). In Tinto's research, academic and social integration are key factors in accounting for student dropout (Tinto, 1986, 1993). Academic integration is an outcome of students' experience with the academic system and academic communities, while social integration can be influenced by factors such as the degree and quality of contacts within faculty members (Tinto, 1993), active learning, fulfilment of expectations for college, student involvement, and self-efficacy (Braxton et al., 2000).

Although the concepts of social and academic integration are frequently employed in the literature to describe the extent to which students gain meaningful membership of the academic and social worlds of the university 'these concepts are rarely discussed in detail, and analyses of how such academic and social integration takes place are lacking' (Wilcox et al., 2005, p. 708). Wilcox et al. (2005) contributes to the understanding of the social lives of the students 
whereas the present paper aims to give insights into activities that can be used to stimulate both academic and social integration.

Tinto (1997) points out that the balance between academic and social integration varies over time for the individual student. He argues that for many students the social integration will be most important in the beginning of their studies, whereas academic integration gradually becomes more important for their persistence. Likewise, Wilcox et al. (2005) show that for first year university students academic integration takes a secondary position to social integration. When students enter university, they are in a transition phase. Wilcox et al. (2005, p. 713) show that in this phase 'Students have an urgent need to belong, to identify with others, to find a safe place and to negotiate their new identities as university students, and friendship is about having friendly faces around and making initial contacts which may or may not develop into friendships'. Hence, it is important to assist this transition, to have enabling structures that can help the students construct a new identity, feel secure, and make new friends - however long these friendships may last.

\subsection{How can integration be achieved? The use of peer learning}

Often students' participation in university classrooms is relatively passive. Learning becomes what Fischer and Grant (1983) has labelled a 'spectator sport' dominated by faculty talk. And some students like this. In terms of learning, however, it is better for students to be involved than to be passive. Hence, the facilitated study groups (described later) are based on the idea that learning is improved when students are actively involved and when they share their learning with peers in a positive manner. This is not something new; Astin (1987) raised these points more than 20 years ago. Surprisingly, many university classrooms are still less than involving and student learning still appears to be a spectator sport combined with reading and writing in solitude.

For the past 25 years, there has been increasing focus on activities which encourage students learning from each other. In higher education, the different practices and concepts are all based on the idea that there is educational benefit in letting students work together, thereby teach and learn from each other, away from teachers and supervisors. Well-know practices are cooperative learning (Kagan, 2007), collaborative learning (Bruffee, 1999), peer tutoring (Falchikov, 2001). For the purpose of this paper, we use the concept peer learning as an overarching concept to cover the different types of activities where learning and teaching is distributed among students. According to Boud and Lee (2005), peer learning can be understood as a two-way, reciprocal 
learning activity. This refers to the network of learning relationships distributed among students. Hence, peer learning can be seen as a 'horizontal' pedagogy where learning is distributed among peers instead of relying on teachers.

The concept of the peer, however, is not clearly defined (Havnes, 2008). Even though a peer should be someone of the same social standing (Falchikov, 2001), it varies whether the peers all belong to the same cohort or whether one of them is an older student; it could also be a student from another degree programme. Another unclear aspect of peer learning is whether the peer learning activity is integrated into the structure of the course or not. While the majority of research agrees that teachers play an important role in promoting peer learning, there is no agreement on the importance of teachers being present during the peer learning activity. The activity can take place in the classroom with a teacher being present. Peer learning can also take place outside the classroom, but still be an integrated part of the degree programme (this was the case of the project reported in this paper). Finally, peer learning outside any formal structure can be critical in integrating students socially and academically. Both Havnes (2008) and Boud and Lee (2005) have reported on peer learning as a vital component in 'becoming a student' or 'becoming an academic'. As Haves explains: 'The organised part of a university course creates opportunities for learning, but it definitely does not explain the whole process of learning. The process expands beyond instruction and enters the sphere where learners create learning contexts in collaboration with peers' (2008, p. 198). Socialisation into these learning contexts is important for social and academic integration, as shown by Tinto. Thereby peer learning becomes important.

\section{The case - enhancing social and academic integration}

In 2008, Aarhus University $(\mathrm{AU})^{2}$ published a report concerning students' experience of their study environment (AU, 2008a, 2008b). It is based on a survey sent to all students and shows that students at AU generally are satisfied with their studies. The Danish School of Education (DPU) ${ }^{3}$, however, stands out with the poorest study environment and the least satisfied students among all eight faculties at AU. The degree programme in educational psychology is a case in point, being among the lowest scoring at DPU. The report showed that factors with strong relation to students' well-being were: the sense of belonging to the degree programme, likelihood of social interaction with other students,

\footnotetext{
${ }^{2}$ Aarhus University has app. 30.400 students and DPU app. 3800 (2009 numbers).

${ }^{3}$ Danish School of Education, in Danish: Danmarks Pædagogiske Universitetsskole, DPU
} 
and absence of loneliness (AU, 2008b). All these issues can be assumed to correspond with low social and academic integration, which we will return to later. Furthermore, there were low scores on issues such as supervision ${ }^{4}$ and contact with the faculty ${ }^{5}$. These issues, however, were not addressed in the project as it takes strong teacher involvement to improve them.

With this report in mind, we (a research group concerning facilitation of knowledge processes at DPU) ${ }^{6}$ decided to initiate a project which should address the low well-being. The project was directed at students in the postgraduate degree programme in educational psychology. It consisted of three elements: facilitated study groups, a student bar with facilitated activities, and academic identity events. These three elements were chosen in order to address some of the problems highlighted in the analysis of the study environment (AU, 2008b).

We agree with Tinto (1997) and other researchers suggesting that faculty involvement is important for student development. However, in this project we wanted to see how much we could change with minimal faculty involvement. This was done in order to prioritise an instant response to the report on students' low well-being at their study programme. It was also due to the institutional framework that many universities have to deal with: a low lecturer/students ratio. Hence, therefore the activities were outside the classroom and none of them were mandatory.

In order to understand the project, it is necessary to give an introduction to the Danish university system and to the degree programmes at DPU. Also, it is necessary with a primer on facilitation, which is a new contribution to the use of peer learning compared to much of the literature cited so far.

\subsection{Primer on the Danish university system and DPU}

In Denmark, most students finish high school when they are 18 or 19 years old. Quite often they have a 'Sabbatical' year or two where they work and go travelling before they begin at university. This means that they are relatively older than undergraduate students in many other Western countries - although the ministry tries to encourage students to begin studying as soon as they have finished high school. Most students have left home, when they start their

\footnotetext{
${ }^{4}$ Less than $20 \%$ of the students agree that it is easy to get supervision and feedback on their academic achievements (AU, 2008b).

${ }^{5}$ Less than $50 \%$ of the students find it easy to get in contact with faculty (AU, 2008b).

${ }^{6}$ One of the authors is member of this group, while the other author participated in the evaluation of the project.
} 
studies and they have to make enough money to pay for accommodation, food, etc. Generally, education is free from primary school through university. Hence, there are no tuition fees, students only have to pay for books and other study materials. Furthermore, all students are entitled to a taxable study grant (from the Government) of app. 5200 DKK ( 700 EUR) and a loan of 2650 DKK ( 350 EUR) per month. Depending on the standard of living and especially on the costs of accommodation, some students have to take loans and/or work while others do not.

This is a very rough sketch of the Danish university system. For historical reasons, DPU has no bachelor programmes. This means that there are only postgraduate/master programmes. The degree programme in question attracts primarily people with a professional background such as primary school and kindergarten teachers, nurses, physiotherapists, etc (in Demark these are not university degrees). The students are on average 10 years older than 'ordinary' Danish university students, many of then have supplementary work while studying, and for many the degree programme is a continuing education rather than their primary higher education, and many of them have a family with children (AU, 2008b). Most often, the students commute to university, some have several hours of transport. Also, the majority have multiple obligations outside campus. Due to their age, family situation, and the fact that going to university is only one in a number of obligations that the students have during their everyday life, the students at DPU may be less interested in making friends compared to undergraduates commencing their first degree. Also, making friends can be more difficult at a commuter institution like DPU, where people only meet once or twice a week during large lectures.

While a Norwegian study (Hovdhaugen, 2009) shows that drops-outs may in fact transfer to other studies, this is not likely to be the case at DPU. There are no data on dropout and transfer rates from DPU's degree programmes ${ }^{7}$. However, as these are postgraduate programmes where the majority of the students already possess a first degree and often years of professional experience, it is unlikely that the transfer rate is high. Rather, when students drop out they go back to their previous or a similar job.

\subsection{Primer on facilitation and how it is used in the project}

While the use of peer learning and study groups are both widespread and well researched, the use of facilitated study groups is not. In facilitation, the use of

\footnotetext{
${ }^{7}$ Completion rates are measured, but attrition rates are not. This is due to the fact that students can remain enrolled even though they are no longer active and may de facto be dropouts.
} 
peers is important whether this is through peer learning, peer supervision or peer support (Heron, 2000)

To facilitate means to assist, to aid, or to make easy. A facilitator is somebody who helps a group to accomplish what they want. Hence, the facilitator is not deciding the goal of the group's work; he or she is merely helping the group achieve this goal. The facilitator is responsible for designing and running the process leading the group towards a result. Consequently, a facilitator is an expert on process not on content and has a number of tools and techniques for designing the process (see e.g. Doyle and Straus, 1982; Justice and Jamieson, 2006).

Facilitation is a practical not an academic discipline. It stems from different fields such as community development, mediation and process consultation and is used for a number of different purposes from facilitative leadership (Bens, 2006), to handling complex group processes (Ghais, 2005), and to improving meetings (Doyle and Straus, 1982). Nevertheless, there is a certain educational rationale and perception of learning inherent in the methods and thinking underlying facilitation practices. However, most often this is not discussed explicitly. John Heron's 'The complete facilitator's handbook' (Heron, 2000 ) is an exception as he is very explicit about the thoughts on learning which constitute the basis of his facilitation practice.

In Heron's view, learning has four components: Practical, conceptual, imaginal, and experiential. These can be depicted as a pyramid where experiential learning is the foundation, people learn from experience. Each type complements and supports the other. Another important tenet of Heron's educational rationale is co-operation with peers. He claims that students only can become self-directed learners in reciprocal relations with other selfdirecting students. Thereby group-based learning and peer feedback on practice and experience become important tools for facilitating learning. Facilitation has primarily been used for groups of adults. Hence, the underlying educational rationale concerns, but may not be limited to, the fields of tertiary, adult, and continuing education. It rests on the premise that student learning is selfdirected, based on the individual's exercise of intelligence, choice, and interest. The primary responsibility for learning thereby rests with the self-directing learner. Consequently, a teacher becomes a facilitator of self-directed learning (Heron, 2000). In Denmark, facilitation is also inspired by positive psychology (e.g. Linley and Joseph, 2004; Seligman, 1998) and by appreciative inquiry (Ludema et al., 2001). The use of personal-constructive questions, which are mentioned later, are signs hereof. 
In our case, it is central that the study groups are facilitated and that the facilitator is a peer, not an older student. What is a facilitator? We use Heron's definition that a facilitator is 'a person who has the role of empowering participants to learn in an experimental group' (2000, p. 1). By choosing a peer as facilitator, we are emphasising an important tenet of facilitation namely that a facilitator is an expert on the process not the content. If the facilitator is an older student, the study group will tend to rely on the older student to know the 'right answer' and thereby to be an expert on the content. Also, an older student may have difficulties keeping the focus on personal and experiential learning if the other students expect him/her to have the right answers. Hence, there will be less emphasis on active and subjective learning when using an older, more knowledgeable student as peer.

\subsection{The project 'Improving the study environment through facilitation'}

The postgraduate degree programme in educational psychology admits app. 250 students each year. Unfortunately, de facto dropout is relatively high and fewer than $3 \%$ complete their studies within the two-year period that is the official duration of the degree programme. This constitutes a problem for the university. It is an economic problem when students do not complete their exams, because a large part of university funding is based on the number of completed exams. Furthermore, it is a (minor) problem, when they do not complete on time as a larger sum of money are rewarded for students completing within the official duration of the degree programme.

The project was initiated with a call for potential facilitators among the students. Through a two-day workshop 17 students learned how to facilitate their own study group and to use peer learning. Apart from lectures on the field of facilitation, the workshop was dominated by practical training in facilitation, e.g. how to keep a discussion focussed and to interrupt very talkative types, how to use different techniques to make sure everybody has been heard, and how to use questions to support learning. After the workshop, groups of 10-14 students were formed and assigned one of the facilitators who had been on the workshop.

Each group met for one hour before every lecture (in total 15 times) discussing the texts for the lecture. The facilitator guided the group through the process, making sure that the discussions were focussed and that everybody had a say. The processes used varied, but usually consisted of a combination of silent reflection on a question, followed by discussion in pairs and might end with a 
'round robin'. Thereby, everybody had a chance to reflect and discuss the text without somebody dominating the group discussions. The questions were either 'academic-critical' or 'personal-constructive'. Academic-critical questions are the type of questions usually used in academia. These were supplemented with personal-constructive questions in order to increase the students' subjective relevancy of the text. Personal-constructive questions allow students to connect their personal and professional experiences to the content of the texts. By listening to the others' experiences, they come to notice the differences in views and experiences across the classroom. Hence, the students learned together.

As far as the study groups are concerned, these are not something new. It is the use of facilitation which is new. The students had 'ordinary' study groups at $1^{\text {st }}$ semester and the faculty usually encourage students to form study groups. Sometimes teachers help construct the groups e.g. based on geography so students coming from afar can travel and work together on the train. The main difference between ordinary study groups and facilitated study groups is that the facilitated study groups make use of a facilitator who is responsible for structuring the time and guiding the group's work towards the desired outcome. In ordinary study groups, students are self-organising which most often means there is no organisation of structure to the groups meetings and nobody to ensure discussions stay focused.

The data used for this paper were collected as part of the evaluation of the project. The evaluation consisted of observations of study-group meetings as well as qualitative interviews and focus groups interviews with 15 study-group facilitators. Furthermore, a questionnaire with both closed and open-ended questions was handed out at the last lecture of the semester. Everybody present in the room answered the questionnaire, which gave a response rate of $70 \%$ of the total cohort. In relation to the data collection, it should be noted that one of us was part of the team implementing the project, while the other took part of the evaluation. Hence one of us was an insider in relation to this research. Although, this is quite common within educational research (see e.g. Sikes and Potts, 2008), it is not without problems. ${ }^{8}$

\footnotetext{
${ }^{8}$ As mentioned in Adriansen and Madsen (2009), there are both advantages and disadvantages when conducting research on the inside. Being an insider in relation to one's interviewees gives the advantage of having a shared history and a close knowledge of the context. The disadvantages concern power relations and presupposed shared understanding. We have addressed the disadvantages in a number of ways. Firstly by being aware of the insider role from the outset and addressing the questions of positionality and power relations explicitly. Secondly by using an outsider for the data collection/evaluation, this means having an outsider to question the presupposed shared understanding in the interview situation. Finally, it has been beneficial to have both an insider and an outsider perspective when analysing and data and writing this paper.
} 


\subsection{Findings}

In the following, we present findings of this multi-method, qualitative and quantitative study of the effects of using facilitated study groups. Although it is possible to understand and describe the project as to separate studies, a qualitative and a quantitative, we will not report our project in that manner. While we describe the analysis in two separate sections, the reader should understand our study as representing different dimensions of a multidimensional study.

\section{Quantitative findings}

The quantitative findings can be measured in two different ways: The survey on well-being and the enrolments for next semester.

The project led to a remarkable improvement in the students' well-being measured on a number of parameters as seen in table 1. The table compares data from the end of the project with the 2007 study from Aarhus University (AU, 2008a). Before the project, educational psychology had low scores on most variables compared to the rest of DPU. Likewise, DPU had low scores compared to the other faculties at Aarhus University, which can be seen in the table comparing DPU to AU. 


\begin{tabular}{|c|c|c|c|c|c|}
\hline & Percentage agreeing to the statement & $\begin{array}{c}\mathbf{A U} \\
\mathbf{2 0 0 7}\end{array}$ & $\begin{array}{l}\text { DPU } \\
2007\end{array}$ & $\begin{array}{c}\text { EP } \\
2007\end{array}$ & $\begin{array}{c}\text { EP } \\
2009\end{array}$ \\
\hline 1 & $\begin{array}{l}\text { The likelihood of social interaction with my fellow } \\
\text { students is high }\end{array}$ & 72 & 32 & 29 & 74 \\
\hline 2 & In general, the other students are forthcoming & 82 & 78 & 80 & 91 \\
\hline 3 & I feel lonely - on a daily basis on campus & 9 & 16 & 19 & 8 \\
\hline 4 & I feel lonely - on a daily basis off campus & 6 & 5 & 5 & 8 \\
\hline 5 & I feel a sense of belonging to the degree programme & 55 & 24 & 21 & 60 \\
\hline 6 & $\begin{array}{l}\text { Generally, my well-being is high when participating } \\
\text { in the programme }\end{array}$ & 83 & 69 & 67 & 84 \\
\hline 7 & $\begin{array}{l}\text { The programme has contributed to my sense of } \\
\text { belonging to an academic community }\end{array}$ & 74 & 54 & 48 & 70 \\
\hline 8 & $\begin{array}{l}\text { My interest in the programme's academic field has } \\
\text { grown since I began studying }\end{array}$ & 85 & 88 & 90 & 90 \\
\hline 9 & $\begin{array}{l}\text { My degree programme has contributed to clarifying } \\
\text { what kind of job I would like when I finish my } \\
\text { studies }\end{array}$ & 43 & 33 & 32 & 32 \\
\hline
\end{tabular}

AU - Aarhus University, DPU - Danish School of Education, EP - Educational Psychology, EP 2009 - Educational Psychology post intervention

We argue that the questions can be seen as relating to social and academic integration, although they have not been phrased with this in mind. ${ }^{9}$ The first three questions can be seen as concerning to social integration. Question 4 is a control question relating to question 3 on loneliness. The questions 5 and 6 concern both social and academic integration, while questions 7-9 relate to academic integration.

As the table illustrates, the most remarkable is the increase in 'sense of belonging to the degree programme'. This has tripled. We find this to be both an element of social and of academic integration. The other aspect of both social

\footnotetext{
${ }^{9}$ As we used the questions from the 2007 survey from Aarhus University, we did not phrase the questions ourselves. In the report from $\mathrm{AU}(2008 \mathrm{a}, 2008 \mathrm{~b})$, there is no mentioning of academic and social integration.
} 
and academic integration 'my well-being is high when participating in the programme' has also increased although not as significantly as the 'sense of belonging'. In general, however, it is primarily the elements relating to social integration that have improved. Another remarkable result is for instance the increase in 'a high likelihood of social interaction with fellow students'. This aspect of social integration has more than doubled. The score on 'the other students are forthcoming' has also increased even though this was high already. The final social integration element, loneliness on campus, has also been improved. The number of lonely students has more than halved. This result is especially remarkable when comparing to the number of lonely students off campus, which has increased. We do not know the cause of this increase, but do not assume it has anything to do with the project.

In terms of elements linking to academic integration, the picture is more blurred. There has been a significant increase in the number of students who feel that 'the programme has contributed to my sense of belonging to an academic community'. But the other two elements have not changed at all. For one of them, 'my interest in the programme's academic field has grown since I began studying' was already high (90\%). However, the other one, 'my degree programme has contributed to clarifying what kind of job I would like when I finish my studies' was fairly low with $32 \%$. At DPU in general, it was $33 \%$ and at $\mathrm{AU}$ in general $43 \%$. Hence, it is not likely that we can reach a very high score here. It is noticeable, however, that there has been no improvement.

Looking at these results, we dare say that the project has improved the social and academic integration. From the outset, we had students who were very interested in the programme's academic field (no 8) and who found that the other students were forthcoming (no 2). But they appeared not to feel a sense of belonging, neither to the degree programme (no 5) nor to the academic community (no 7). It was striking that the likelihood of social interaction was considered to be low (no 1). Hence, it is not enough that the other students are forthcoming, where there is no or only little interaction with them. Therefore, we consider interaction to be a key to the success observed here. Apparently, the students do not have or make sufficient interaction themselves; interaction has to be facilitated and preferably in relation to the academic content in order to achieve both social and academic integration. We conclude that the introduction of facilitated study groups has increased the interaction among the students, leading directly to a remarkable improvement in this element (no 1). There is an important derived outcome of increased interaction and this is an increase in the sense of belonging (no 5 and 7). Hence, by increasing the interaction, we can also increase the sense of belonging and reduce the feeling 
of loneliness (no 3). Naturally, these elements also have a positive influence on the general well-being (no 6). However, it is more difficult to affect the ideas about future job opportunities (no 9). We tried to address this by making an event about 'academic identity' (not reported in this paper). But as the results show, this event had little effect. Apparently, the facilitated study groups had little effect in relation to this particular aspect.

In summing up, we assert that both the social and the academic integration have been improved during the project period. Therefore, retention is an expected outcome of the project. Retention, however, can be measured in a more direct way than increased social and academic belonging. We decided to measure retention by looking at the number of students deciding to continue the next semester. There was a decrease in dropout between $2^{\text {nd }}$ and $3^{\text {rd }}$ semester from $12 \%$ in 2008 to $3 \%$ in 2009. In this respect, retention was improved. When combining this number with the increased well-being revealed in the table, we feel confident that student dropout will continue to decrease and that a higher number of students will finish on time.

\section{Qualitative findings}

The purpose of the qualitative element of the study was to understand from the facilitators' and students' perspective how the facilitated study groups worked. Both interviews and observations were used. The facilitated study groups became a way to make DPU a more familiar and better known place for the participating students. Because the study groups both served as a forum for discussing the readings and as a place to get to know each other, they served two needs: social and academic integration without having to sacrifice one for the other.

The facilitated study groups were also seen as places for integration and thereby worked as stepping stones for inclusion by the students. One of the facilitators admitted that before the facilitation of the study groups she would 'sneak' in and out of class and then study in solitude off campus. Now she feels 'at home' at campus and has become happier for studying. Another facilitator explained:

"I have become aware of the importance of participation in order to feel welcome. It is about taking responsibility for your own participation. [...] Academically it has meant that one takes it more serious 'I have to read this, because we are going to discuss it tomorrow [in the study group]. That has made one hang on a bit more" (Helen). 
Concerning the outcome of the facilitated study groups, typical answers were: 'I found out that I was not the only person who didn't understanding the text', 'I got a social network', and 'Discussing the text gave a much deeper understanding'.

In relation to the lectures, the facilitated study groups allowed students to connect their personal experiences to the lecture content, to relate to the content, and participate in discussion with peers. Two of the facilitators explained:

"On a number of occasions, they [the members of the study group] have come to me after the lecture and said that it was cool that we had discussed the concepts and talked about how to understand it in a practice context. That it had really helped in understanding the lecture" (Sue).

"When we came to a lecture, we sat down next to each other. When she began the lecture - it's exactly those questions and exactly those frustrations she discusses! Then we began nodding and say 'Wow, we have understood something'. It was really 'wow'. That we had managed to bring that forward in our own discussion [in the study group]" (Helen).

Also the possibility of articulating points of view in the facilitated groups contributed to the student behaviour in the lecture halls. Quite often, the teachers also noted the change in student behaviour. The teachers talked about it among themselves and some of them came to us after the project and told that they had experienced a better prepared crowd, and more students who participated by asking questions during class as well as better quality questions. One of the facilitators explained why they had a different behaviour in class:

"To have to articulate something, that has always been weighty, because you have it all in your head but to have to articulate it and receive feedback, listen to yourself say all those difficult things and mess it up... It [the study group] has meant that it felt safer asking questions during a lecture" (Sarah).

We find that the use of questions was important to the work in the study groups. Using both academic-critical and personal-constructive questions in the facilitation process required students to rethink both what they knew and become personally involved in deciding what they knew and how they knew it. In this manner, facilitation can induce students to take ownership over the learning process. Moreover, the interviewees also pointed out that besides using the discussions in the facilitated study groups to get an overview of the academic content they also worked as a place of connecting the content to the students' life in a wider perspective. This effect can probably be ascribed to the 
use of personal-constructive questions, which means that the students share their professional experiences. The students noted the benefits of meeting the diversity of views and experiences that marked different members of the study group.

During the interview, one student reflected on the difference between these groups and conventional study groups. In the latter, there were two members who "gradually were left behind. This experience I've never had in the facilitated group". She explained that this probably was due both to the facilitation, which means that everybody is heard, and to the personal-constructive questions, which means that everybody has something to say. Another student framed it this way:

"The benefit of being facilitated is that it [the discussion] is managed in a manner which means that it doesn't end up in 'coffee talk'. It is somehow delimited... the purpose - as I see it - is both social and academic. And really it is about making those two things merge" (Mary).

As seen in the quote above, both academic and social integration is an outcome of the facilitated study groups. During the interviews, it was significant that many students considered academic and social integration closely related:

"I think there are some elements in it... I think there is a knowledge element. And then I think there is a social element. For instance I have begun to talk with more people at the study and have become friends with some of them on Facebook. There is a social element in getting to know more people and having more people to greet. That has increased my desire to study because I feel like coming here... feel like having a break with some of the others and like that. And at the same time, I think it is really cool in terms of knowledge, to get to apply some of the concepts in practice. And to have a focus on 'Why is it that I study this?'. Because at times at the Module 1 I read without reflecting and then-after this facilitation stuff - you read in a different way. You think 'How can I use his text? Or what interests me in this text?'. That's one of the contributions [of facilitated study groups], I find" (Kathrin).

While it is important to bear in mind that these results reflect the whole project and not only the facilitated study groups, we find that most of the improvement in well-being and the feeling of being better integrated socially and academically are due to the work in the facilitated study groups. This was confirmed during the interviews with the facilitators. 


\section{Discussion and concluding remarks}

In this paper, we have moved the discussion beyond the recognition of the importance of social and academic involvement to how it can be done practically especially in a setting where student involvement does not come easy due to the students' distance from university and time constrains in relation to committing to university life.

While Tinto claims that 'if academic and social involvement or integration is to occur, it must occur in the classroom' (1997, p. 599), we assumed it could be different. Hence, we constructed new spaces where academic and social integration could happen. However, by no means do we neglect that faculty involvement is important for student development, we merely show that academic and social integration also takes place outside the classroom.

The paper was based on Tinto's thesis that increased social and academic integration will lead to increased retention. And further that peer learning can be used as a means for social and academic integration. In the paper, we have reported from a project using facilitated study groups as forum for leer learning and hence as a means to increase retention. Our survey showed a remarkable improvement in student well-bring when comparing to the 2007 survey from Aarhus University. The analysis of the survey revealed that the facilitated study groups had contributed to a noteworthy increase in the elements relating to social integration, while some elements of what could be considered academic integration were lacking behind. Hence, there is room for further work within this area. However, the interview with the facilitators did not confirm a bias towards social integration. The analysis further showed there was a decrease in dropouts from $2^{\text {nd }}$ to $3^{\text {rd }}$ semester. The project shows how academic and social integration can be achieved with minimum teacher member involvement. This is done by relying on the students' own resources, using peer learning and facilitating these activities.

\section{Acknowledgements}

We are indebted to all the students who participated in the project and in particular to the student facilitators without whom the project would never have succeeded. We are also grateful for their participation in the interviews. The project idea was conceived in collaboration with associate professor $\mathrm{Ib}$ Ravn and special consultant Nina Tange, DPU, who both have provided valuable comments on this paper. Dean of education at DPU Hans Siggaard kindly found the resources available for financing the project. Without the help 
from assistant professors Eva Silberschmidt Viala and Lisser Rye Ejersbo, the project itself would not have been possible. A previous and much shorter version of this paper was presented at the SRHE 2009 conference. We are grateful for the comments received here. All the usual disclaimers apply.

\section{References}

Adriansen, H.K. and L.M. Madsen (2009) Studying the making of geographical knowledge: The implications of insider interviews. Norsk Geografisk Tidsskrift Norwegian Journal of Geography, 63, 3: 145-153.

Astin, A. (1987) Achieving educational excellence. San Fransisco, Jossey-Bass.

AU (2008a) Studiemiljø 2007, rapport 1: Aarhus Universitet - hovedresultater og nøgletal. Studieudvalget, Aarhus Universitet.

http://www.au.dk/uddkvalitet/analyse/studiemiljoe2007/hovedrapport

AU (2008b) Studiemiljø 2007, rapport 7: Resultater og nøgletal, Danmarks Prdagogiske Universitetesskole, Aarhus Universitet. Studieudvalget, Aarhus Universitet. http://www.au.dk/uddkvalitet/analyse/studiemiljoe2007/dpu

Bens, I. (2006) Facilitating to lead! Leadership strategies for a networked world. Jossey-Bass, USA

Boud, D. and A. Lee (2005) 'Peer learning' as pedagogic discourse for research education. Studies in Higher Education, 30, 5: 501-516.

Braxton, J.M., Sullivan, A.S. and Johnson, R.M. (1997): Appraising Tinto's theory of college student departure. In J.C. Smart (ed.): Higher Education: Handbook of theory and research, Vol.12: 107-164, NY: Agathon.

Braxton, J.M., Milem, J.F. and Sullivan, A.S. (2000): The influence of active learning on the college student departure process - towards a revision of Tinto's theory. The Journal of Higher Education, vol.7 (5): 569-590.

Bruffee, K.A. (1999) Collaborative learning: higher education, interdependence and the authority of knowledge. Baltimore, Johns Hopkins University Press

Falchikov, N. (2001) Learning together: peer tutoring in higher education. London, Routledge. 
Fischer, C.G. and G.E. Grant (1983) Intellectual levels in classrooms. In C.L. Ellner and C.P. Barned (eds.) Studies of college teaching, pp. 47-60. Lexington, D.C. Heath

Doyle, Michael and David Straus (1982) How to make meetings work. Jove, USA

Ghais, Suzanne (2005) Extreme facilitation: Guiding groups through controversy and complexity. Jossey-Bass, USA

Haves, A. (2008). Peer-mediated learning beyond the curriculum. Studies in Higher Education, 33, 2: 193-204.

Heron, J. (2000) The complete facilitator's handbook. Kogan Page, Diss.

Hovdhaugen, E. (2009) Transfer and dropout: different forms of student departure in Norway. Studies in Higher Education 34, 1: 1-17

Justice, T. and D.W. Jamieson (2006) The facilitator's fieldbook. Amacom, USA

Kagan, S. (2007) Cooperative Learning. Hawker Brownlow Education, Heatherton.

Linley, P. Alex and Joseph, Stephen (eds.) (2004). Positive Psychology in Practice. John Wiley \& Sons, Inc.

Ludema, J.D., D.L. Cooperrider and F.J. Barrett (2001) Appreciative inquiry: the power of the unconditional positive question. In P. Reason (ed.) Handbook of action research, pp. 189-199. Sage Publications, Trowbridge.

OECD (2006): Background report. Meeting of OECD Education Ministers. Higher Education: Quality, Equity and Efficiency. 27-28 June 2006. (Accessed 16 February 2010 at http://www.oecd.org/dataoecd/30/7/36960580.pdf)

OECD (2009): Education at a glance. OECD indicators.(Accessed 12 March 2010 at http://www.oecd.org/dataoecd/41/25/43636332.pdf).

Ozga, J.; Sukhnandan, L. (1998): Undergraduate Non-Completion: Developing an Explanatory Model. Higher Education Quarterly 52(3), July (316-333) 
Pascarella, E.T. \& Terenzini, P.T. (2005): How College Affects Students. Volume 2. A Third Decade of Research. San Francisco, CA: Jossey-Bass

Seligman, M.E.P. (1998). Learned Optimism. New York: Pocket Books (Simon and Schuster).

Seymour, E. (2002): Tracking the processes of change in US undergraduate Education in Science, Mathematics, Engineering, and Technology. Science Education 86, 1: 79-105

Seymour, E. and Hewitt, N. (1997): Taking about leaving: Why undergraduates leave the sciences. Boulder, CO: Westview.

Sikes, P. and P. Potts (eds.) (2008) Researching education from the inside: Investigations from within. Routledge.

Tinto, V. (1975): Dropout from Higher Education: A Theoretical Synthesis of Recent Research. Review of Educational Research 45(1) 89-125

Tinto, V. (1986): Theories of college student departure revisited, In J.C. Smart (ed): Higher Education: Handbook of theory and research, Vol.2: 359-384, NY: Agathon.

Tinto, V. (1993): Learning college: Rethinking the course and cures of student attrition. Chicago: University of Chicago Press.

Tinto, V. (1997): Classrooms as Communities, exploring the Educational Character of Students Persistence. The Journal of Higher Education, 68, 6: 599-623.

Ulriksen, L., Madsen, L.M. and H.T. Holmegaard (forthcoming): What do we know about explanations for dropout/opt-out among young people from STM higher education programs? Studies in Higher Education.

Wilcox, P., Winn, S. and M. Fyvie-Gauld (2005): 'It was nothing to do with the university, it was just the people': the role of social support in the first-year experience of higher education. Studies in Higher Education vol. 30 (6): 707-722. 


\section{ABSTRACT}

Attrition is a problem of concern in many higher education institutions. Research has shown that retention can be improved if students experience social and academic integration. This paper presents results from a project aimed at using peer learning to increase students' social and academic integration and thereby retention. A second aim was to achieve this with minimal faculty involvement. Social and academic integration is often seen as restricted to happen in the classroom and being facilitated by teachers. However, faculty resources are often limited and therefore we posed the challenge to minimize teacher involvement in the project. By teaching students how to facilitate peer learning in study groups, academic and social integration was obtained outside the classroom. The work in the study groups was facilitated by 'real' peers - not older students. The paper shows that it is possible to obtain academic and especially social integration outside the classroom. 


\section{ABSTRACT}

Attrition is a problem of concern in many higher education institutions. Research has shown that retention can be improved if students experience social and academic integration. This paper presents results from a project aimed at using peer learning to increase students' social and academic integration and thereby retention. A second aim was to achieve this with minimal faculty involvement. Social and academic integration is often seen as restricted to happen in the classroom and being facilitated by teachers. However, faculty resources are often limited and therefore we posed the challenge to minimize teacher involvement in the project. By teaching students how to facilitate peer learning in study groups, academic and social integration was obtained outside the classroom. The work in the study groups was facilitated by 'real' peers - not older students. The paper shows that it is possible to obtain academic and especially social integration outside the classroom. 